Ammar Kh Al-Nori BDS, MSc (Lect)

\section{Fracture Resistance of Premolars with Different Filling Techniques}

\author{
Department of Prosthetic Dentistry \\ College of Dentistry, University of Mosul
}

\begin{abstract}
Aims: To evaluate the fracture resistance of premolars with mesio-occluso-distal (MOD) preparations with resin composite using different incremental techniques when submitted to occlusal load. Materials and Methods: Fifty premolars were used and randomly divided into five groups of ten teeth each. The teeth in group I were prepared and not restored. The teeth in group II were restored in vertical technique. Teeth in group III were restored in horizontal technique. Teeth in group IV were restored in oblique technique. Teeth in groups II, III and IV were restored using Exite adhesive system and Tetric hybrid composite. Teeth in group $\mathrm{V}$ were restored in horizontal technique using combinations of Tetric flowable composite and Tetric hybrid composite. After thermocycling, the teeth were tested under universal compression machine. The data obtained in this research were subjected to analysis of variance and Duncan's Multiple Range Test. Results: Both groups V and IV significantly increase the fracture resistance of teeth over groups II and III. Conclusions: Selection and appropriate use of materials, better placement technique and control polymerization shrinkage may increase the resistance of teeth to fracture with Class II resin composite restorations.

Key Words: Resin composite, fracture resistance, polymerization shrinkage.
\end{abstract}

Al-Nori AKh. Fracture Resistance of Premolars with Different Filling Techniques. Al-Rafidain Dent J. 2007; 7(SpIss): 103S-108S.

Received:13/3/2007

Sent to Referees: $13 / 3 / 2007$

Accepted for Publication: 10/4/2007

\section{INTRODUCTION}

During the polymerization of bonded resin composite restoration, a complex process occurs. As the curing proceeds contraction and flow gradually decrease and the resin composite stiffness increase. As a result, the stress begins to grow and can cause adhesion failure ${ }^{(1-3)}$.

Polymerization shrinkage that occurs during the curing of resin composite results in significant stresses in the composite tooth bond and surrounding tooth structure ${ }^{(4-6)}$.

Techniques used to minimize the effect of polymerization shrinkage like progressive photo polymerization and incremental insertion technique ${ }^{(7,8)}$.

In the progressive photo polymerization, the composite is irradiated by a low initial light intensity followed by normal light intensity. With low light intensity, the resin stays for a longer period in a flow state whereby volumetric change can be compensated for by this continued flow of the resin composite. Afterwards, high light intensities are necessary for a complete polymerization and optimal mechanical properties ${ }^{(9-11)}$.

The incremental technique is based on polymerization with resin composite layers less than $2 \mathrm{~mm}$ thick. The purpose of the incremental techniques is to minimize the stress generated by polymerization contraction, inserting resin layers into the cavity reducing the bonded areas and allows the resin composite to flow at the free surfaces. As a result, we have a lower $\mathrm{C}$ factor (configuration) which is the ratio between bonded and unbounded surfaces $^{(12-14)}$.

The goal of this research is to evaluate the fracture resistance of premolars with MOD preparations restored with different incremental techniques when submitted to occlusal load.

\section{MATERIALS AND METHODS}

Fifty maxillary premolar teeth extracted for orthodontic purposes were collected immediately after extraction and placed in distilled water before being evaluated for use in this research. All of teeth selected were intact, non-carious and unrestored. They were cleaned with 
pumice. Any tooth with crack was excluded. Each tooth was mounted in a plastic cylinder with the long axis of the tooth perpendicular to the plane of surveyor. The level of cold cure resin was brought to be $2 \mathrm{~mm}$ below the cemento-enamel junction. They were then stored in distilled water.

Class II MOD cavities were prepared with parallel walls and no a proximal boxes in all teeth with number 245 carbide bur in a high speed hand-piece under air water spray. The bur was replaced after each five preparations. For the purpose of standardization, the surveyor was used. The plate of the surveyor was fixed in a horizontal plane, then the ring was fixed on the plate. The parallel sided carbide bur, which moves at fixed horizontal plane, was passed through the parallel walls making them parallel to each other. The resulting cavity was $1 / 3$ of the intercuspal distance. The occluso-pulpal depth of the cavity was $1 / 2$ of the length of the crown measured from buccal cusp tip to the cemento-enamel junction. All these dimensions were measured using a digital vernier to standardize the cavity preparations. A round bur attached to an angled hand-piece running in a conventional speed along the internal line angles making them round.

After preparation, the teeth were randomly divided into five groups of ten teeth each. The teeth in group I were not restored. With exception of the placement technique, teeth in groups II, III and IV were restored using Excite adhesive system (Ivoclar Vivadent AG, Fl-9494 Schaan / Liechtenstein) and Tetric hybrid resin composite (Ivoclar Vivadent AG, Fl9494 Schaan / Liechtenstein) following the manufacturer's instruction.

Teeth in group $\mathrm{V}$ were restored using Excite adhesive system and a combination of both Tetric flowable composite (Ivoclar Vivadent AG, Fl-9494 Schaan/ Liechtenstein) and Tetric hybrid composite.

Teeth in group II were restored in three incremental vertical layers: First filling and polymerization the proximal faces and then the central.

Teeth in group III were restored in three incremental horizontal layers.

Teeth in group IV were restored in incremental oblique layers: First the material was placed against the buccal wall up to the pulpal floor and polymerized, then the material was placed against the lingual wall up to the pulpal floor and polymerized. This procedure was repeated to fill the preparation in four layers.

Teeth in group $\mathrm{V}$ were restored in three horizontal layers: The first layer with Tetric flowable composite. The second and third layers with Tetric ceram composite.

The teeth of the five groups were thermocycled between 5 to $55 \pm 2{ }^{\circ} \mathrm{C}$ for 100 cycles and stored in distilled water for 24 hours at $37^{\circ} \mathrm{C}$ in an incubator before testing.

The teeth were tested for resistance to fracture with a universal compressive machine (Engineering rest equipment, Model CN 472, Soil test, USA). A 5 mm diameter cross head with a speed of $0.5 \mathrm{~mm} / \mathrm{min}$ was used touching only the occlusal incline of the facial and lingual cusps until fracture occurred.

\section{RESULTS}

The minimum and maximum values for the load that required to produce teeth fracture were listed in Table (1). The data were analyzed using ANOVA, Table (2). Duncan's Multiple Range Test was used to compare the significantly different groups, Figure (1).

The results of this research showed that both group V $(94.61+13.64 \mathrm{Kg})$ and group IV $(93.59 \pm 13.87 \mathrm{Kg})$ significantly increase the fracture resistance of teeth over group II $(73.52 \pm 15.34 \mathrm{Kg})$ and group III $(71.46 \pm 7.97 \mathrm{Kg})$. Teeth in group I $(48.67 \pm 6.1 \mathrm{Kg})$ demonstrated significantly the least fracture resistance among the test groups.

There was no significant difference between groups II and III. Also, there was no significant difference between groups IV and $\mathrm{V}$.

\section{DISCUSSION}

The preparation made were proportional to the tooth dimensions ( $1 / 3$ of the intercuspal distance and $1 / 2$ of the length of the crown). This may lead to the same fracture resistance of all teeth evaluated in this research. 
The polymerization shrinkage of a resin composite can create contraction forces that may disrupt the bond to cavity walls and lead to microleakage ${ }^{(2,15)}$.

If the composite-tooth bond is able to withstand the deformation stresses induced by the contracting composite can cause deformation of tooth structure and degree of cuspal movement which predisposes the tooth to fracture ${ }^{(16-18)}$.

In this research, it was observed that the obliquely placed composite showed significantly higher value of fracture resistance and this may be due to the fact that in this technique, wedge shaped composite increments are placed further prevent distortion of cavity walls and inserting the resin into the cavity by wedge shaped layers reduces the $C$ factor which allows the resin to flow at free surfaces ${ }^{(10,19)}$. As a result, the stresses of polymerization shrinkage will be reduced which lead to increase the resistance of teeth to fracture. This finding came with the finding of Bharadwaj et al ${ }^{(20)}$.

In this research, it was observed that the horizontal incremental technique using combinations of both flowable and hybrid composite showed significantly higher values of fracture resistance. The goal of the selective composite technique is to use different combinations of composite materials (flowable and hybrid) to restore enamel and dentin. Enamel is a highly mineralized tissue and contain 92\% inorganic hydroxyapatite by volume. Dentin is only $45 \%$ inorganic. So, bonding resin composite to the dentinal surfaces is considerably more complex and less reliable than bonding resin composite to acidetched enamel. ${ }^{(21,22)}$ It also has been demonstrated that when bonding to deep dentin, a decrease in bond strength may occur ${ }^{(23)}$. This may explain the adhesive failure at the dentin-composite restoration interface even through high bond strength. As a consequence, composite can be deformed under occlusal load ${ }^{(24)}$. The use of a flowable composite may improve the marginal adaptation to dentin ${ }^{(25)}$ and help to create an elasticity gradient between the dentin and the hybrid composite, thus the flowable composite may improve the effectiveness of the dentin bonding agent in counteracting the polymerization stress at the restoration-dentin interface ${ }^{(8,22)}$ and as a result, increasing the resistance of teeth to fracture.

Table (1): Descriptive statistics for the load (in Kg) required to produce teeth fracture

\begin{tabular}{ccccc}
\hline Group & Number & Minimum Value & Maximum Value & Mean \pm SD \\
\hline I & 10 & 40.9 & 56.1 & $48.67 \pm 6.1077$ \\
II & 10 & 55.4 & 97.8 & $73.52 \pm 15.3498$ \\
III & 10 & 56.1 & 82.3 & $71.463 \pm 7.9726$ \\
IV & 10 & 71.5 & 110.7 & $93.59 \pm 13.8798$ \\
V & 10 & 67.8 & 116.3 & $94.613 \pm 13.6458$ \\
\hline
\end{tabular}

SD: Standard deviation.

Table (2): Analysis of variance for the effect of filling techniques on fracture resistance of teeth

\begin{tabular}{cccccc}
\hline & SS & Df & MS & F-value & $\boldsymbol{p}$-value \\
\hline Between Groups & 14288.266 & 4 & 3572.066 & \multirow{2}{*}{24.968} & 0.000 \\
Within Groups & 6438.030 & 45 & 143.067 & & \\
Total & 20726.296 & 49 & & & \\
\hline
\end{tabular}

SS: Sum of square; MS: Mean squares; Df: Degree of freedom. 


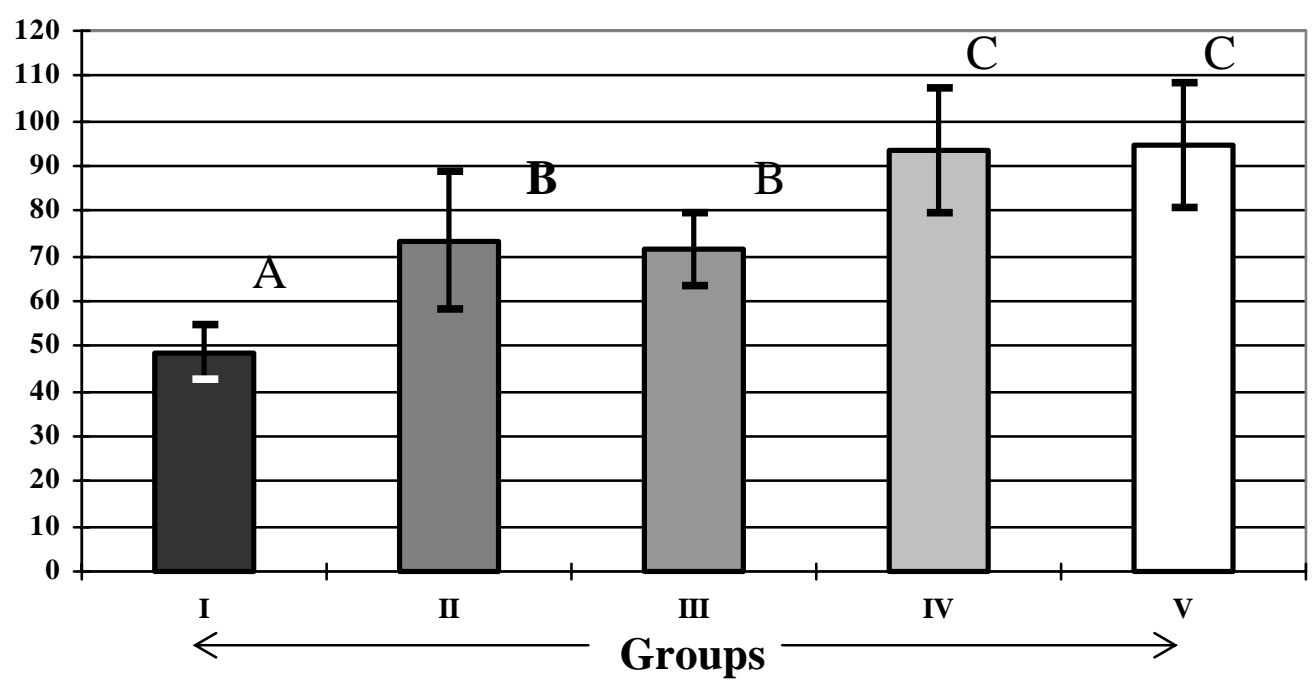

Figure (1): Duncan's Multiple Range test for the effect of filling technique on fracture resistance of teeth

Means with different letters were statistically significant $(p \leq 0.001)$

\section{CONCLUSIONS}

Selection and appropriate use of materials, better placement technique and control polymerization shrinkage may increase the resistance of teeth to fracture with Class II resin composite restorations.

Horizontal technique using flowable and hybrid composites and oblique technique significantly increase the resistance of teeth to fracture.

\section{REFERENCES}

1. Koran P, Kurschner R. Effect of sequential versus continuous irradiation of a light $\mathrm{Cu}-$ red resin composite on shrinkage, viscosity, adhesion and degree of polymerization. Am J Dent. 1998; 10: 17-22.

2. Rosin M, Urban A, Cartner G, Bernhardt D, Splieth C, Meyer G. Polymerization shrinkage strain and microleakage in dentin bordered cavities of chemically and light cured restorative materials. Dent Mater. 2002; 18: 521-528.

3. Aujyap M, Vishan K. Influence of curing lights and modes on cross-link density of dental composites. Oper Dent. 2004; 29: 410-415.

4. Sakaguchi R, Peters M, Nelson S. Effect of polymerization contraction in composite restoration. J Dent. 1992; 20: 178-182.

5. Versluis A, Tantbirojn D, Douglas W. Distribution of transient properties during polymerization of a light initiated restorative composite. Dent Mater. 2004; 20: 543-553.
6. Silva A, Pereira G, Dias C, Paulillo L. Effect of the composite photo activation mode on microtensile bond strength and knoop microhardness. Dent Mater. 2006; 22: 203-210.

7. Alessandro D, Reis A, Ballester R. Polymerization shrinkage effect of constraint and filling technique in composite restorations. Dent Mater. 2004; 20: 237-240.

8. Braga R, Ballester R, Ferracane J. Factors involved in the development of polymerization shrinkage stress in resin composites. Dent Mater. 2005; 21: 962-970.

9. Neiva I, Andrada M, Baratievi L. An in vitro study of the effect of restorative technique on marginal leakage in posterior composite. Oper Dent. 1998; 23: 282-289.

10. Deliperi S, Bradwell D. An alternative method to reduce polymerization shrinkage in direct posterior composite restorations. J Am Dent Assoc. 2002; 133: 1387-1392.

11. Lie N, Felten K, Trixner K, Hickel R, Kunzelmann K. Shrinkage behavior of resin based composite irradiated with modern curing units. Dent Mater. 2005; 21: 483-489.

12. Feilzer A, De Gee A, Davidson C. Setting stress in composite resin in relation to configuration of the restoration. J Dent Res. 1987; 66: 16361639. 
13. Daniel F, Margas V. The spectrum of composites. New technique. $J$ Am $D$ ent Assoc. 2000; 131: 26-30.

14. Nikolaenko S, Lohbaner U, Roggendrof M, Petschelt A, Dasch W, Frankerberger R. Influence of $C$ factor and layering technique on microtensile bond strength to dentin. Dent Mater. 2004; 20: 579-585.

15. Carvalho R, Pereira J, Yoshiyama M. A review of polymerization contraction: The influences of stress developed versus stress relief. Oper Dent. 1996; 21: 17-24.

16. Wieczkowski E. Effect of composite restorations on resistance to cuspal fracture in posterior teeth. $J$ Prosthet Dent. 1987; 57: 431-435.

17. Suliman A, Boyer D, Lakes R. Polymerization shrinkage of composite resin: Comparison with tooth deformation. J Prosthet Dent. 1994; 71: 712.

18. Armstrong S, Keller J, Boyer D. The influence of water storage and $C$ factor on the dentin-resin composite microtensile bond strength and debond pathway utilizing a filled and unfilled adhesive resin. Dent Mater. 2001; 17: 268-276.

19. Stansburg J, Lemon M, Lu H, Dring
X, Lin Y, Ge J. Conversion-dependent shrinkage stress and strain in dental resins and composites. Dent Mater. 2005; 21; 56-67.

20. Bharadwaj N, Solomon P, Parames A. Tooth restored with composite resin. A comparative analysis. Trends Biomater Artif Organs. 2002; 15: 57-60.

21. Pashley D, Carvalho R. Dentin permeability and dentin adhesion. $J$ Dent. 1997; 25: 355-372.

22. Atlar N, Turgul N, Gungar H. The effect of flowable resin composites as gingival increments on the microleakage of resin composites. Oper Dent. 2004; 29: 26-31.

23. Ogata M, Okuda M, Nakajima M, Pereira P, Tagami J. influence of the direction of tubules on bond strength to dentin. Oper Dent. 2001; 26: 27-35.

24. Kempscholte C, Davidson C. Complete marginal seal of Class $\mathrm{V}$ composite restorations affected by increased flexibility. J Dent Res. 1990; 69: 1240-1244.

25. Li Q, Jepen S, Albers H, Eberhard J. Flowable materials as an intermediate layer could improve the marginal and internal adaptation of composite restorations in Class V cavities. Dent Mater. 2006; 22: 250-253. 